\title{
KONDISI KREDIT USAHA SELAMA PANDEMI DI PROVINSI JAWA
}

\section{BARAT}

\author{
Berta Dian Theodora \\ Fakultas Teknik dan IlmuKomputer \\ UniversitasIndraprasta PGRI Jakarta \\ Berta.dtos@gmail.com
}

Dikirim : 21Juni 2021. Direvisi : 23Juni 2021. Dipublikasikan : 30 Juni 2021

\begin{abstract}
ABSTRAK
Nilai kredit yang disalurkan kepada pelaku usaha terus meningkat setiap tahunnya, namun saat terjadi kondisi pandemic terlihat jumlah kredit usaha yang diberikan bank setiap bulannya fluktuatif. Provinsi Jawa Barat merupakan provinsi dengan jumlah penduduk terbesar yaitu 49,94 juta jiwa, secara administrative pemerintahannya terbagi menjadi 27 kabupaten/kota. Penelitian ini bertujuan untuk mengetahui kondisi kredit usaha di setiap kabupaten dan kota selama masa pandemi. Jenis data penelitian adalah data sekunder yang berasaldari Bank Indonesia dan BPS Provinsi Jawa Barat. Penelitian kuantitatif dan metode deskriptif dengan data sampel adalah kredit usaha UMKM kabupaten dan kota di Jawa Barat daribulan April 2020 sampai dengan April 2021. Hasil yang diperoleh kredit usaha kecil dan menengah mengalami peningkatan namun kredit usaha mikro menurun setiap bulannya. Kredit usaha merupakan bagian dari modal finansial dan merupakan salah satu faktor yang menentukan jumlah output, sehingga penambahan kredit usaha diharapkan dapat menjadi faktor pendorong pertumbuhan ekonomi dan pada akhirnya menyerap tenaga kerja.
\end{abstract}

Keywords: Kredit, UMKM, Jawa Barat,

\section{A. PENDAhULUAN}

Sektor Usaha Mikro, Kecil dan Menengah (UMKM) memiliki peran penting dalam perekonomiankarena UMKM adalah salah satu sektor ekonomi yang memiliki kontribusi besar dan merupakan alternative solusi bag permasalahan sosial seperti kemiskinan dan pengangguran. Usaha Mikro Kecil dan Menengah (UMKM) di Jawa Barat merupakan aktivitas perekonomian yang mampu bertahan dalam krisis ekonomi pada tahun 1998 dan 2000 (Goeltom, 2005), kondisi UMKM di Jawa Barat tidak terlepas dari dukungan perbankan dalam penyaluran kredit usaha. Kondisi 4 tahuns ebelum terjadinya pandemic yaitu pada tahun 2016 -2019 (gambar.1) jumlah kredit UMKM yang diberikan oleh pihak bank mengalami pertumbuhan dari tahun ketahunnya dengan rata-rata $10,26 \%$ pertahun?. Kondisi modal kerja yang berfluktuasi terutama ketika mengalami penurunanakan mengakibatkantingkat outputproduksi (produkdomestik regional bruto/PDRB) menurun sehingga dikhawatirkan penyerapan jumlahtenaga kerja yang kurangmaksiman. Secaraumum, kondisi Tingkat PengangguranTerbuka (TPT) dan PDRB di ProvinsiJawaBarat terlihat pada gambar 2. 
Tingkat pengangguranterbuka dan PDRB (gambar 2) di ProvinsiJawaBarat yang diperhitungkansecaratahunan, memperlihatkanbahwadaritahun 2013 - 2019 ketikaperekonomianberjalandengan normal makaperubahan pada TPT berkisardiangka $8 \%$ - 9\% namunketikaterjadikondisipandemimakaangka TPT meningkatmenjadidiatas 10\% tepatnyaberada di angka 10,46 (bps.go.id.2021) dan PDRB Provinsi pada tahunterjadinyapandemi, kondisi PDRB daritahun 2019 ketahun 2020 terjadipenurunansebesar 16,32\%.

Peningkatan TPT dan penurunan PDRB yang dihitung dalam periode tahunan menjadi gambaran bahwa selama terjadinya pandemic ditahun 2020 telah mengakibatkan perekonomian menurun. Untuk meningkatakan kembali perekonomian, pemerintah mengupayakan stimulus bagi para pelaku ekonomi dengan berbagai cara untuk meningkatkan kembali perekonomian diantaranya adalah dengan memberikan stimulus kredit usaha agar pengusaha terus menjalankan usahanya dan melakukan produksi.

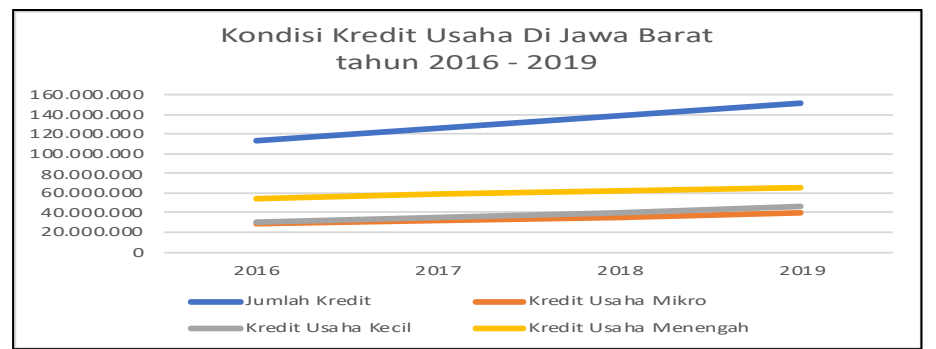

Gambar 1. KondisiKredit Usaha di Jawa Barat tahun 2016 -2019 Sumber : Bank Indonesia.2021
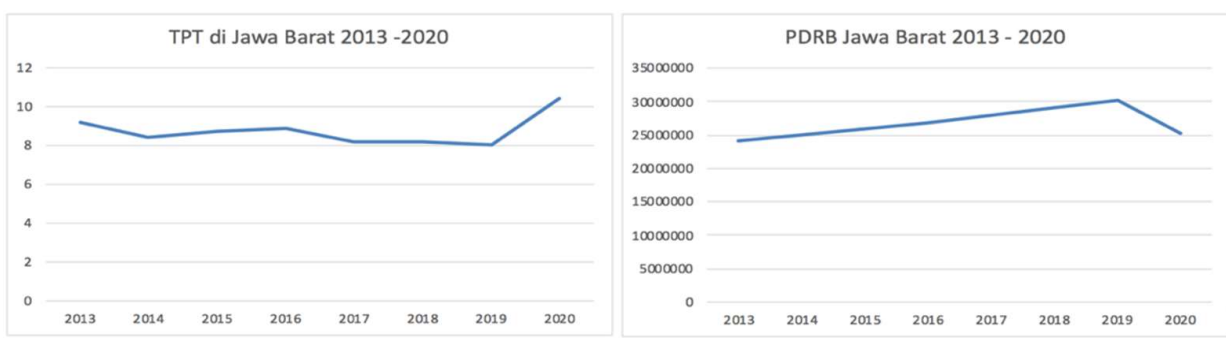

Gambar 2. Kondisi TPT dan PDRB di ProvinsiJawa Barat Tahun 2013-2020

Sumber : BPS Jawa Barat. 2021

Data Bank Indonesia (BI) secaranaisonalmenunjukkan per Juli 2020 kredit UMKM turun $0,5 \%$ secara year on year (yoy), halinilebihdalam $0,1 \%$ dari bulan sebelumnya sehingga pemerintah dan perbankan semakin gencar dalam penyaluran kredit kesektor usaha mikro, kecil dan menengah. BI mencatat terjadinya kontraksi sebesar $-2,7 \%$ yoy diakhir bulan Februari 2021 pada realisasi kredit UMKM, dan hal ini sejalan dengan penurunan yang terjadi dibulan Januari 2021 yaitu terkontraksi sebesar $-2,4 \%$. Kontraksi ini disumbang dari usaha mikro yang turun sebesar $-23,6 \%$ yoy, namun segmen kecil dan menengah pada dua bulan pertama tercatat mengalami kenaikan sebesar 4,3\% dan 5,3\%. Data Statistik Perbankan Indonesia di OJK mencatatkan bahwa kredit UMKM terus mengalami 
penurunan sejak Maret hingga Juli 2020 dan mulai tumbuh di bulanAgustus 2020 (Republika.co.id.2020).

Namun bagaimanakah kondisi kredit usaha di ProvinsiJawaBarat khususnya pada setiap kabupaten dan kota selama terjadinya pandemi, apakah tingkat kredit usaha mengalami penurunan ataukah peningkatan gun amenjaga modal usaha. Kondisi pandemi yang jelas berpengaruh terhadap perekonomian terlihat pada gambar.3 yaitu PDRB tahunan Provinsi JawaBarat mengalami penurunan dari tahun 2019 ketahun 2020, namun apakah kredit usaha sebagai stimulus dari pemerintah kepada wirausaha-wirausaha mikro, kecil dan menengah telah terserap secara maksimal ataukah elama masa pandemi para pengusaha lebih memilih mengurangi kredit karena usaha tidak berproduksi sehingga tidak memerlukan modal tambahan?.

\section{B. KAJIAN PUSTAKA}

Kredit usaha yang merupakan bagian dari financial capital dapat menjadi salah satu faktor yang menentukanj umlah output, sehingga penambahan kredit usaha diharapkan dapat menjadi faktor pendorong pertumbuhan ekonomi. Sektor kredit usaha selain berpengaruh terhadap output perekonomian, memilikipengaruh juga terhadap sektor tenaga kerja atau kondisi pengangguran, keberadaan tingkat pengangguran terbuka (TPT) dapat menjadi indikator yang mengukur tingkat penawaran tenaga kerja dan keterserapan tenaga kerja oleh pasar kerja.

Dewan Koperasi Indonesia (DEKOPIN) mengartikan UMKM sebagai pelaku usaha ekonomi yang dikategorikan sebagai usaha dengan skala kecil, menggunakan teknologi tradisional, dan dikelola secara sederhana. (Laena, 2010) dan The Organisation for Economic Co-operation and Development (OECD) menyebutkan bahwa UMKM adalah perusahaan independen yang mempekerjakan karyawan kurang dari jumlah tertentu. Batasan jumlah ini bervariasi antar negara, dimana paling umum UMKM adalah perusahaan yang mempekerjakan karyawan kurang dari 250 karyawan, Usaha kecil umumnya adalah usaha yang mempekerjakan karyawan kurang dari 50 karyawan, sementara usaha mikro adalah usaha yang mempekerjakan karyawan paling banyak 10 orang, bahkan dalam beberapa kasus hanya 5 karyawansaja. (OECD, 2005:17).

Undang-UndangNomor 20 Tahun 2008 Tentang Usaha Mikro, Kecil dan Menengah (UU UMKM) Pasal 6 ayat (1), (2), dan (3) memberikan kriteria bagi UMKM yang digolongkan berdasarkan jumlah aset dan omset yang dimiliki sebuah usaha. Adapun kriteria UMKM adalah sebagai berikut:

Tabel 1. Kriteria UMKM

\begin{tabular}{|c|c|c|c|}
\hline \multirow{2}{*}{ No } & \multirow{2}{*}{ Uraian } & \multicolumn{2}{|c|}{ Kriteria } \\
\hline & & Aset (Rp) & PenjualanTahunan (Rp) \\
\hline 1 & Usaha Mikro & $<50$ Juta & $<300$ Juta \\
\hline 2 & Usaha Kecil & $>50$ Juta -500 Juta & > 300 Juta - 2,5 Miliar \\
\hline 3 & Usaha Menengah & $>500$ Juta - 10 Miliar & $>2,5$ Milyar - 50 Miliar \\
\hline
\end{tabular}

Sumber : UU Nomor 20 Tahun 2008

Pemerintahsangatmendorong dan mendukungkeberadaansektor UMKM (Usaha Mikro, Kecil dan Menengah), sebagai penopang tatanan perekonomian 
Indonesia dan keberadaan bank dalam fungsinya sebagai penyalur kredit dapat menjadi salah satuwujudpemerintahdalammendorong dan mendukungkeberadaan UMKM, penyaluran kredit ini harus bermanfaat dan dirasakan langsung oleh para pelaku usaha khusunya sektor UMKM. Secara umum kredit dapat dilihat dari segi tujuan kredit diberikanya itu kredit produktif dan kredit konsumtif, kredit produktif adalah kredit yang digunakan untuk peningkatan usaha atau produksi atau investasi, dan diberikan untuk menghasilkan barang atau jasa,sedangkan kredit konsumtif digunakan untuk konsumsi pribadi, yang tidak menghasilkan pertambahan barang dan jasa

Undang - undangn No.10 Tahun 1998tentangperubahanatas UU No.7 tahun 1992 tentang Perbankan tepatnya pada pasal 1 angka 11 menjelaskan kredit adalah penyediaan uang atau tagihan yang dapat dipersamakan dengan itu, berdasarkanpersetujuanataukesepakatanpinjam-meminjamantara bank dengan pihak lain yang mewajibkan pihak peminjam untuk melunasi utangnya setelahjangkawaktutertentudenganpemberianbunga.

Kasmir (2013) menjelaskan fungsi fasilitas kredit antara lain: 1)meningkatkan daya guna uang, 2) meningkatkanperedaran dan lalulintasuang, 3)meningkatkan daya guna barang, 4) meningkatkan peredaran barang, 5)sebagai alat stabilitas ekonomi, 6) meningkatkan pemerataan pendapatan, 7)meningkatkan hubungan internasional, dan 8) meningkatkan kegairahan berusaha bagi penerima kredit apalagi bagi nasabah yang modalnya terbatas. Pemberian suatu fasilitas kredit mempunyai tujuan tertentu yang tidakakanterlepasdarimisi bank dantujuanutamapemberiankreditadalah:1) Mencarikeuntunganyaituberupabunga yang diterima oleh bank sebagaibalasjasa dan biayaadministrasikredityang dibebankankepadanasabah; 2)Membantuusahanasabah, secarakhususnasabah yang memerlukan dana, baikdana investasimaupun dana untuk modal kerja yang akandapatmengembangkan dan memperluasusahanya; 3)Membantupemerintah, semakinbanyakkredit yang disalurkan oleh pihakperbankan, makaakanmeningkatkanpembangunandiberbagaisektor(Kasmir, 2013).

PrinsipdasardalammenganalisiskreditmenurutVeithzal dan Andria (2007) yaitu: 1)Character:keadaanwatak/sifatdarinasabah, 2) Capital: dana/modal sendiri yang oleh calonnasabah, 3)Capacity: kemampuan yang dimilikicalonnasabahdalammenjalankanusahanyagunamemperolehlaba yang diharapkan, 4) Collateral:barang-barang yang diserahkan oleh nasabahsebagaiagunanterhadapkredit yang diterimanya, 5) Condition of Economic:situasi dan kondisipolitik, sosial, ekonomi, budaya yang mempengaruhikeadaanperekonomian pada suatusaat yang akanmempengaruhikelancaranperusahaancalondebitur, 6)Constraintadalahbatas dan hambatan yang tidakmemungkinkansuatubisnisuntukdilaksanakan pada tepatwaktu.

ProvinsiJawa Barat adalahprovinsidenganpendudukterbanyak, yakni 49,94 Juta Jiwa denganluaswilayah $35.377,76 \mathrm{KM}^{2}$, secaraadministratifpemerintahan di Jawa Barat terbagikedalam 27 kabupaten/ kota, meliputi 18 kabupaten dan 9 kota (Kabupaten Bandung, KabupatenGarut, KabupatenTasikmalaya, KabupatenCiamis, KabupatenPangandaran, KabupatenKuningan, Kabupaten 
Cirebon, KabupatenMajalengka, KabupatenSumedang, KabupatenIndramayu, Kabupaten Subang, KabupatenPurwakarta, KabupatenKarawang, Kabupaten Bekasi, Kabupaten Bandung Barat dan 9 kotayaitu Kota Bogor, Kota Sukabumi, Kota Bandung, Kota Cirebon, Kota Bekasi, Kota Depok, Kota Cimahi, Kota Tasikmalaya, dan Kota Banjar, Kota Bogor, Kota Sukabumi, Kota Bandung, Kota Cirebon, Kota Bekasi, Kota Depok, Kota Cimahi, Kota Tasikmalaya, dan Kota Banjar)

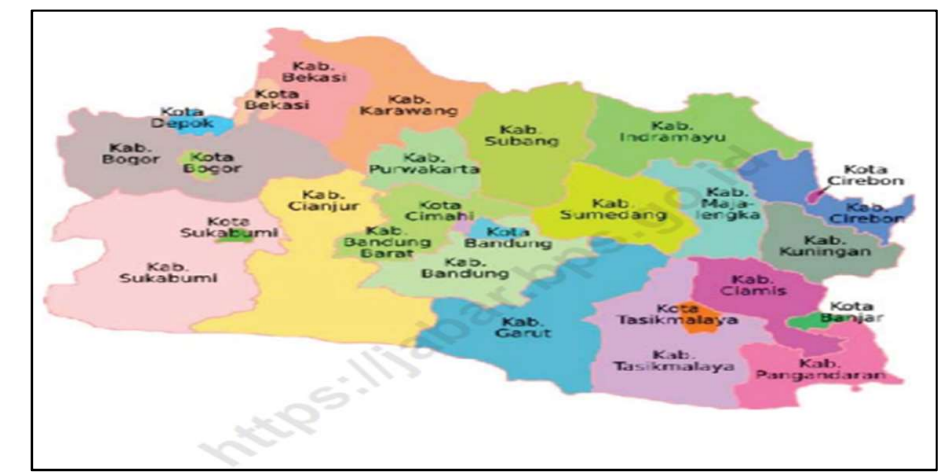

Gambar 3. Pembagian Wilayah AdministratifProvinsiJawa Barat

Sumber: Jabardalam angka. 2020

\section{METODE PENELITIAN}

Penelitianinimemilikitujuanuntukmengetahuikondisipenyalurankreditusaha yang diberikan oleh pihak bank disetiapkabupaten dan kota pada ProvinsiJawaBarat selama masa pandemi. Jenis data penelitianadalah data sekunderberasaldari situs Bank Indonesia (BI) dan Badan Pusat Statistik (BPS) ProvinsiJawa Barat.

Penelitianmenggunakanpendekatankuantitatif dan metodedeskriptifstatistikgunamenggambarkankondisikreditusaha di ProvinsiJawa Barat selamaterjadinyapandemi. Populasipenelitanadalahangkakredit yang disalurkan oleh bank disetiapKabupaten dan Kota dikawasanProvinsiJawa Barat. Sampelpenelitianadalah data kreditusahamikro, kecil dan menengah pada kabupaten dan kota di ProvinsiJawaBarat mulai April 2020 sampai April 2021, yaitukurunwaktuterjadinyapandemi di Indonesia.

\section{HASIL DAN PEMBAHASAN}

Bank adalahlembaga yang menghimpun dan menyalurkan dana masyarakat. $\begin{array}{llll}\text { Pemberiankreditmerupakan salah satufungsipokok bank } & \end{array}$ dalamhalpenyalurandana,Salahsatubentukkredit yang dikenaladalahjeniskreditproduktifkepada UMKM gunamembiayai dan membantukegiatanproduksiusaha. PemberianKreditkepadasektorusahamikro, kecil dan menengahdicatatkansecaraberbeda oleh Bank Indonesia dan kondisipemberiankredit di ProvinsiJawa Baratselamaperiode April 2020 - April 2021 terlihat pada tabel 3.

Nilai kredit yang disalurkankepadausahaterusmeningkatsetiaptahunnya, namunketikaterjadinyakondisipandemiterlihatbahwabesaranjumlahkreditusaha 
yang diberikan oleh pihak bank setiapbulannyamengalamifluktuasi (gambar.5), kredit pada usahakecil dan menengahmengalamipeningkatannamunkredit pada usahamikrosemakinmenurunsetiapbulannya.

Kreditusahamerupakanbagiandarifinancial capital dan menjadi salah satufaktor yang menentukanjumlah output, sehinggapenambahankreditusahadiharapkandapatmenjadifaktorpendorongpertumb uhanekonomi dan pada akhirnyamenyeraptenagakerja.

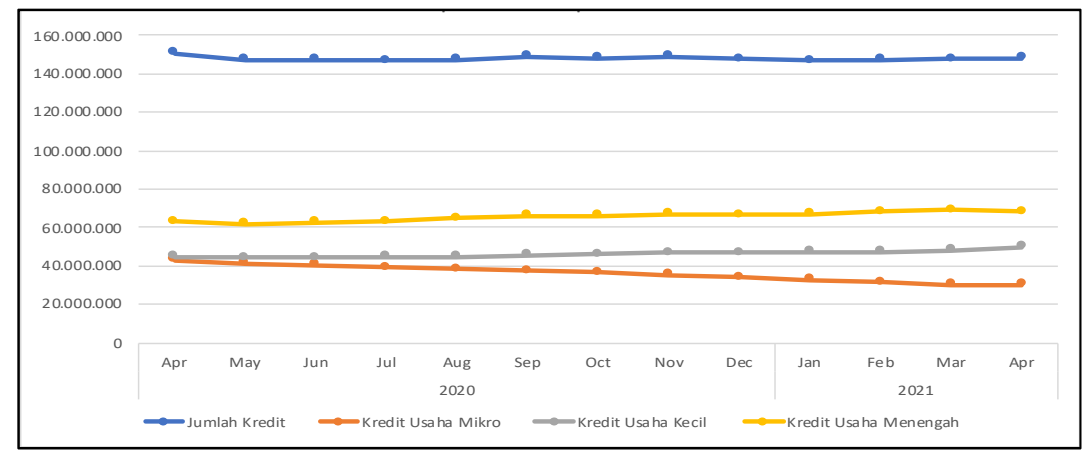

Gambar 4. KondisiKredit UMKM di ProvinsiJawa Barat Sumber: diolah Peneliti.2021

UMKM yang adalahbentukusaha yang didirikansecaraindividu dan atauberkelompokdikalanganmasyarakatmemilikipermodalan yang terbatas dan pinjamandaripihak lain sepertiperbankanmenjadi salah satupilihanuntukmenjalankanusaha. Gambar 4 menunjukkansejakbulanke 2 masa pandemiyaitubulan April 2020 sampaidengan April 2021 angkapenyalurankreditkategoriusahamikromengalamipenurunan, sedangkanjumlahkredit pada usahakecil dan menengahmengalamipeningkatan. Penyalurankreditselama masa pandemidilakukansebagai salah satu stimulus yang diberikanpemerintah agar para pengusahadapatmempertahankanusahanya dan melanjutkanproduksi.

SejakawalpandemiCovid-19 dibulanmaret 2020, pihakpemerintah dan perbankanmulaimemfokuskankreditkepadapengusaha pada tingkatmikro, kecil dan menengah, komitmeniniberlanjutdenganadanya stimulus dan relaksasidaripemerintah dan perbankan, sebagai salah satucontoh, komitmendari salah satu bank BUMN, yaitu PT Bank Negara Indonesia Tbk (BNI) yangmenuangkankebijakan stimulus dan relaksasipemerintahdalam 3 (tiga) strategiutamayaitu:

fasemitigasidampakpandemibagidebiturlewatrestrukturisasikreditterhadaplebihdar i 100.000 debitur; 2) BNI mendorongadaptasi digital bagipelakuusaha; dan 3) lewatpemulihan UMKM terdampakpandemi, sejalandengankomitmentersebut. Pemberiankreditakanmembantuusaha yang memerlukan dana investasiataupun dana modal kerjasehinggausahatersebutdapatberkembang, penyalurankreditturutmembantupemerintah, semakinbanyakkreditdiberikandiharapkanakanmeningkatkanpembangunandiberba gaisektor. (Kontan.co.id.2021) 
Ketikamelihatkondisi di setiapkabupaten dan kota di ProvinsiJawa Barat, terdapatbeberapawilayah yang mengalamipeningkatan dan penurunanpenyalurankredit (tabel 2 dan 3). Kabupaten dan Kota dengantingkatkredittertinggiterlihatpada gambar5, Kota Bandung yang memilikitingkatkredittertinggidiantaraseluruhwilayahadministratifdi

ProvinsiJawaBarat, mengalamipenurunansejak April 2020 hinggaDesember 2020 lalumulaimengalamikenaikan pada Januaritahun 2021 dan semakinmeningkatsampaidengan April 2021 walaupunbelumkembali pada angkasebelumterjadinyapandemi.

Kabupaten Bekasi, Kabupaten Bogor, Kabupaten Bandung dan Kota Bekasi terlihatmengalamikondisifluktuatifsetiapbulannya,

tidakterlihatpenurunandalamjangkawaktuberbulan-bulanseperti yang dialami Kota Bandung. Kondisi pada setiapwilayahkabupaten dan kota di ProvinsiJawa Barat mengenaiangkakredit pada usahamikro, kecil dan menengahterlihat pada tabel 2 dan 3.

Upayapemberdayaanmasyarakatmelaluipeningkatan

UMKM perluselaludilakukanbaik oleh pemerintahmaupunpelakuusahasendiri, pemerintahdiharapkanmembangunlokasi-lokasiusahabaru yang bisamenyeraptenagakerja dan mengembangkanproduk local. (marti'ah.2020).

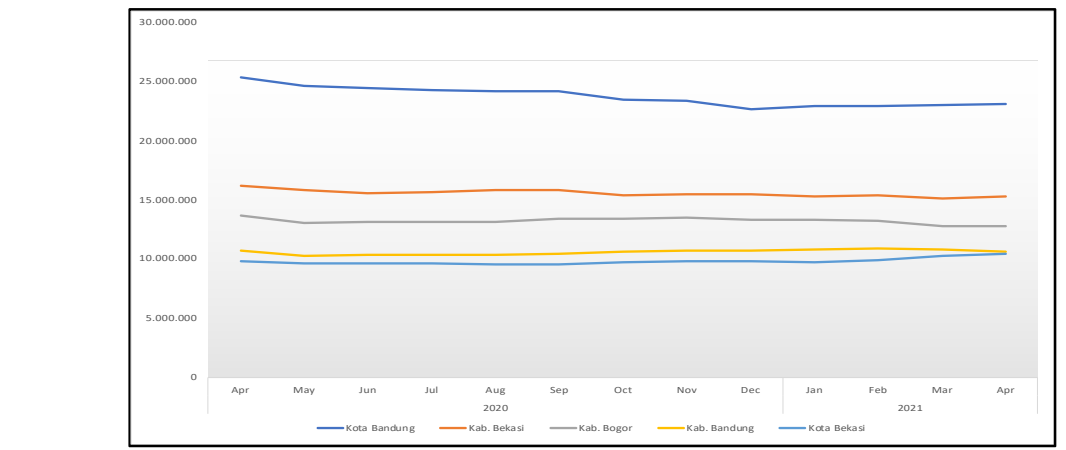

Gambar 5. GrafikKondisiKreditusaha pada 5 wilayahdenganangkakreditterbanyak Sumber: diolah Peneliti.2021

Dalamhalpermodalan, upaya yang telahdilakukan oleh pemerintahsudahcukupbaik, mulaidari program KUR (Putra dan I ketut.2018) sampaidenganpaketkebijakan yang berpihak pada UMKM. Dalamhalpemasaran, strategipengembangan UMKM dapatmemanfaatkanpertumbuhan internet saatini. Pelaku

UMKM dapatmembukapeluanguntukmemperluasjangkauanpasarnyamelaluie-commerce dan jejaring media sosial. Untukdistribusiproduk UMKM kepelanggan, pelaku UMKM dapatmemanfaatkanpertumbuhanperusahaanjasapengiriman yang jumlahnyacukupbanyak, baiktingkatlokalmaupunnasional (Permana.2017). Pertumbuhanekonomi regional dapatditingkatkanmelaluipemberiankreditataupembiayaan UMKM, haliniperludidorong agar para pemilikusahadapatterusberproduksi dan 
semakinmeningkatkegiatanperekonomiandimasyarakatsecaraumum. (Putra dan I Ketut.2018; Anggraini dan Haryad.2020).

Selama masa pandemiterjadipembatasansosial dan fisik yang menyebabkaninteraksijual-belisecaratradisionalsemakinsulitdilakukan dan agar usahadapatterusberjalan, para pemilikusahadisarankanmenggunakanteknologi, terutama pasar digital yang semakinberkembang. Pemerintahdiharapkandapatmembantupengusahauntukmelakukanpelatihanpenjual anproduksecara digital dan perencanaansecarastrategis agar pendapatanmeningkat (Ardiansyah.2020; Apriyanti.2020).

\section{E. SIMPULAN}

Kondisikreditusaha pada kabupaten dan kota di ProvinsiJawa Barat berbedadisetiapkategoriusaha.Secara umum terlihat bahwa sejakJanuari 2021 angka kredit usaha mulai beranjak naik di setiapkabupaten dan kota. Peningkatankredit UMKM pada wilayahkabupaten dan kota di ProvinsiJawa Barat akanmendatangkandampaksecarakhususterhadapjumlah UMKM dan secaraumumkepadapeningkatanperekonomianmasyarakatsekitar. Hal ini terlihat ketika terjadi peningkatan pertumbuhan ekonomi mulai dari Kabupaten, Kota sampai tingkat Provinsi. Peningkatan kredit pada sektor UMKM akan maksimal dirasakan manfaatnya ketika para masyarakat memiliki jiwa kewirausahaansehinggasemakinbanyakbermunculanwirausaha-wirausahabaru (start-up) dalammembukalapanganpekerjaan, adanya jiwa wirausaha dikalangan para start-up akan membantu mereka mengelola resiko dan memiliki kemampuanbertahandalamkondisiapapun.

Hasil yang lebih komprehensif mengenai perkembangan kredit pada wilayah kabupaten dan kota di Provinsi JawaBarat dapat diperoleh jikadilakukanpenelitian yang mencakuprentangwaktusebelumterjadinyapandemi. Penulismenyarankan agar dilakukankajianmenggunakanrentangwaktu yang lebih Panjang sertam empertimbangkan variabel- variabel lain yang mempunyai keterkaitan berdasarkan teori terhadap variabel kredit UMKM, sehingga penelitianlebihmenggambarkankondisikredit di jawabaratsecarakomprehensif.

Tabel 3. Kredit Usaha Di Kabupaten Dan Kota ProvinsiJawa Barat Januari - April 2021

\begin{tabular}{|c|c|c|c|c|c|c|}
\hline \multirow{2}{*}{\multicolumn{3}{|c|}{$\begin{array}{c}\text { Kota/Kabupaten dan Kriteria } \\
\text { Usaha }\end{array}$}} & \multicolumn{4}{|c|}{2021} \\
\hline & & & Jan & $\mathrm{Feb}$ & Mar & Apr \\
\hline \multirow{4}{*}{1} & \multirow{4}{*}{ Kab. Bekasi } & Total & 15.307 .534 & 15.319 .122 & 15.062 .485 & 15.218 .996 \\
\hline & & Mikro & 1.866 .394 & 1.810 .964 & 1.776 .300 & 1.759 .876 \\
\hline & & Kecil & 4.809.991 & 4.806 .830 & 4.779 .498 & 4.978 .449 \\
\hline & & Menengah & 8.631 .149 & 8.701 .327 & 8.506 .687 & 8.480 .672 \\
\hline \multirow{3}{*}{2} & \multirow{3}{*}{ Kab. Purwakarta } & Total & 2.349 .396 & 2.372 .659 & 2.382 .382 & 2.415 .913 \\
\hline & & Mikro & 694.788 & 666.258 & 633.978 & 616.388 \\
\hline & & Kecil & 969.465 & 993.880 & 1.013 .356 & 1.061 .532 \\
\hline
\end{tabular}




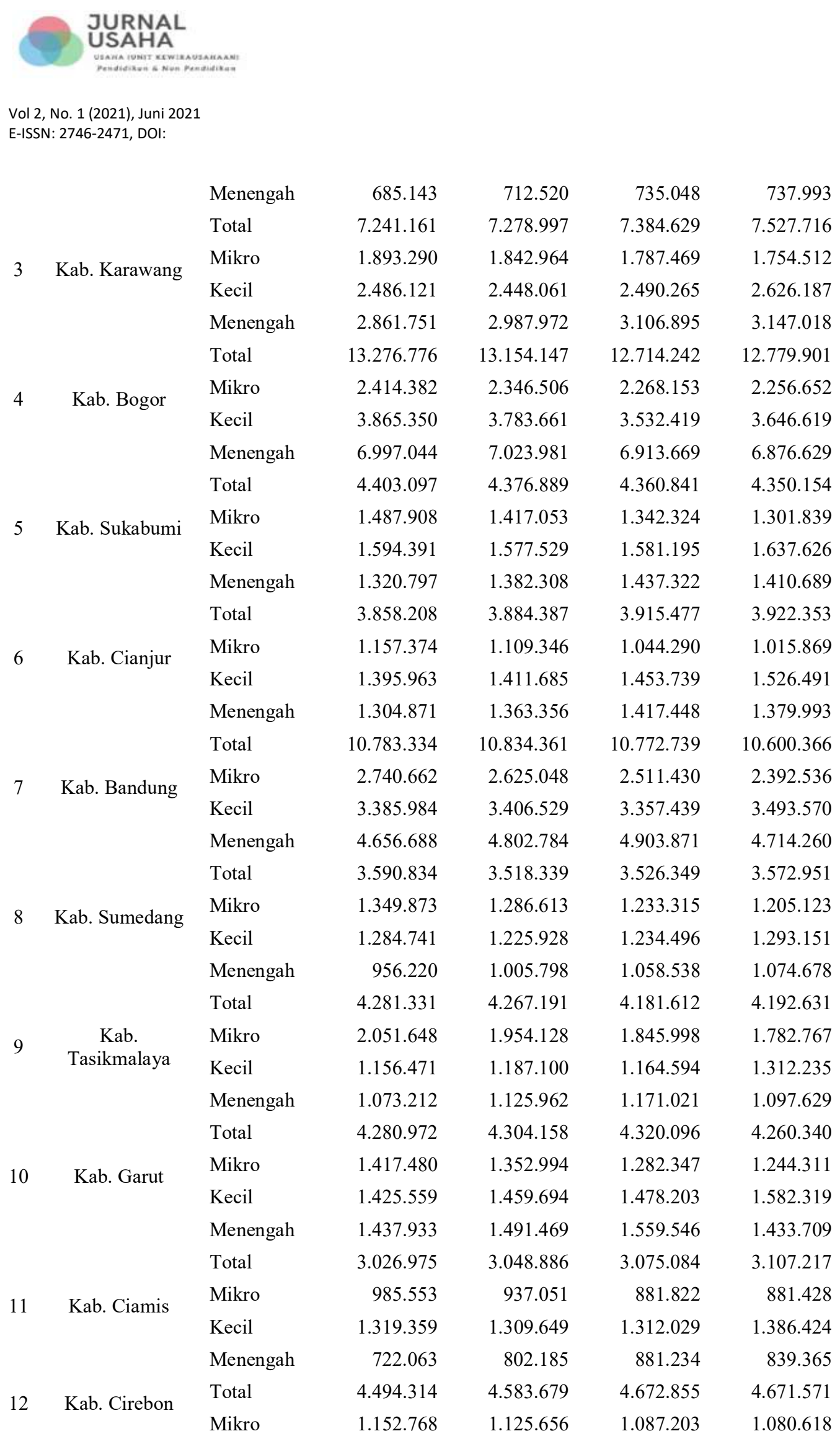




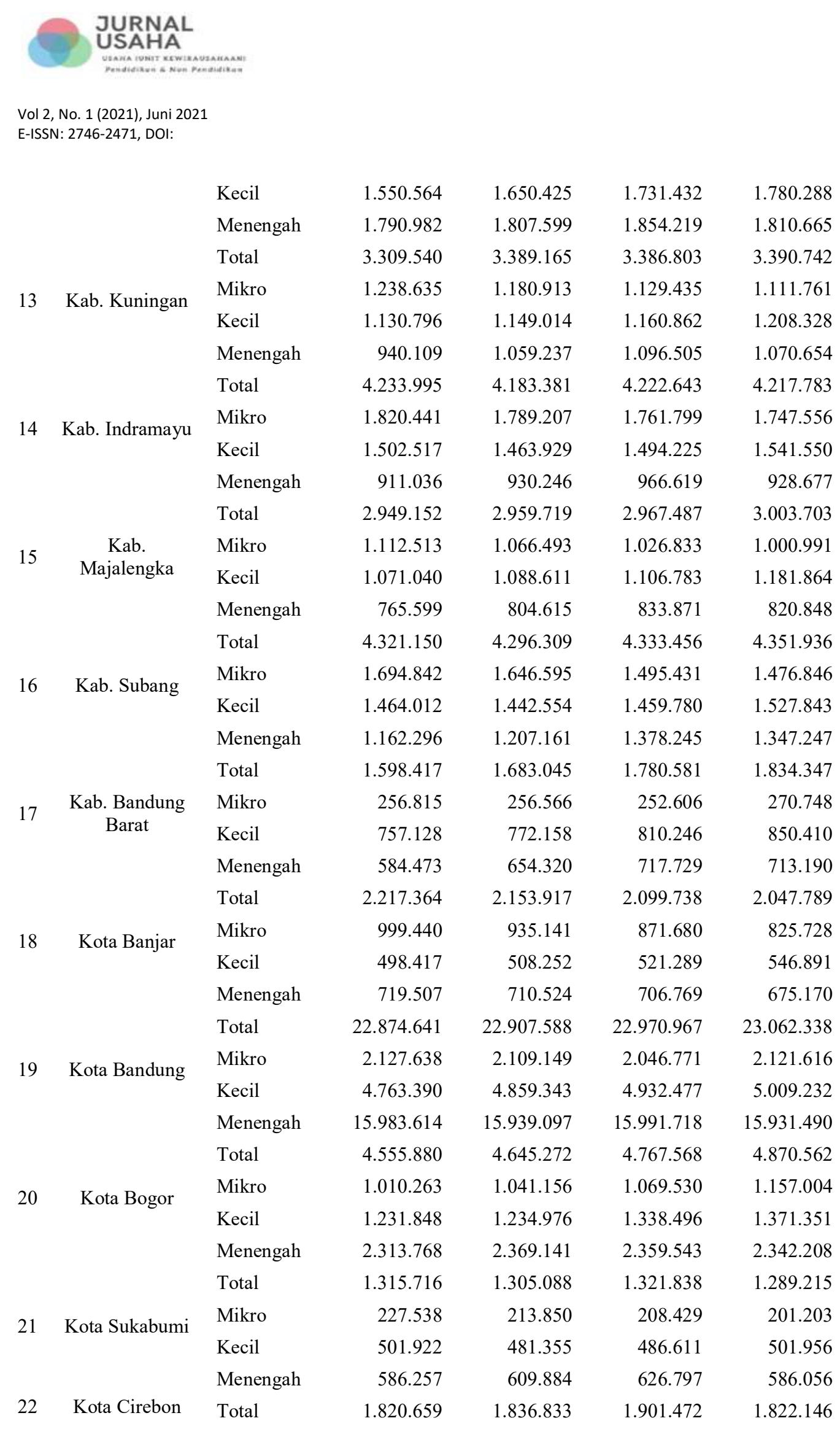




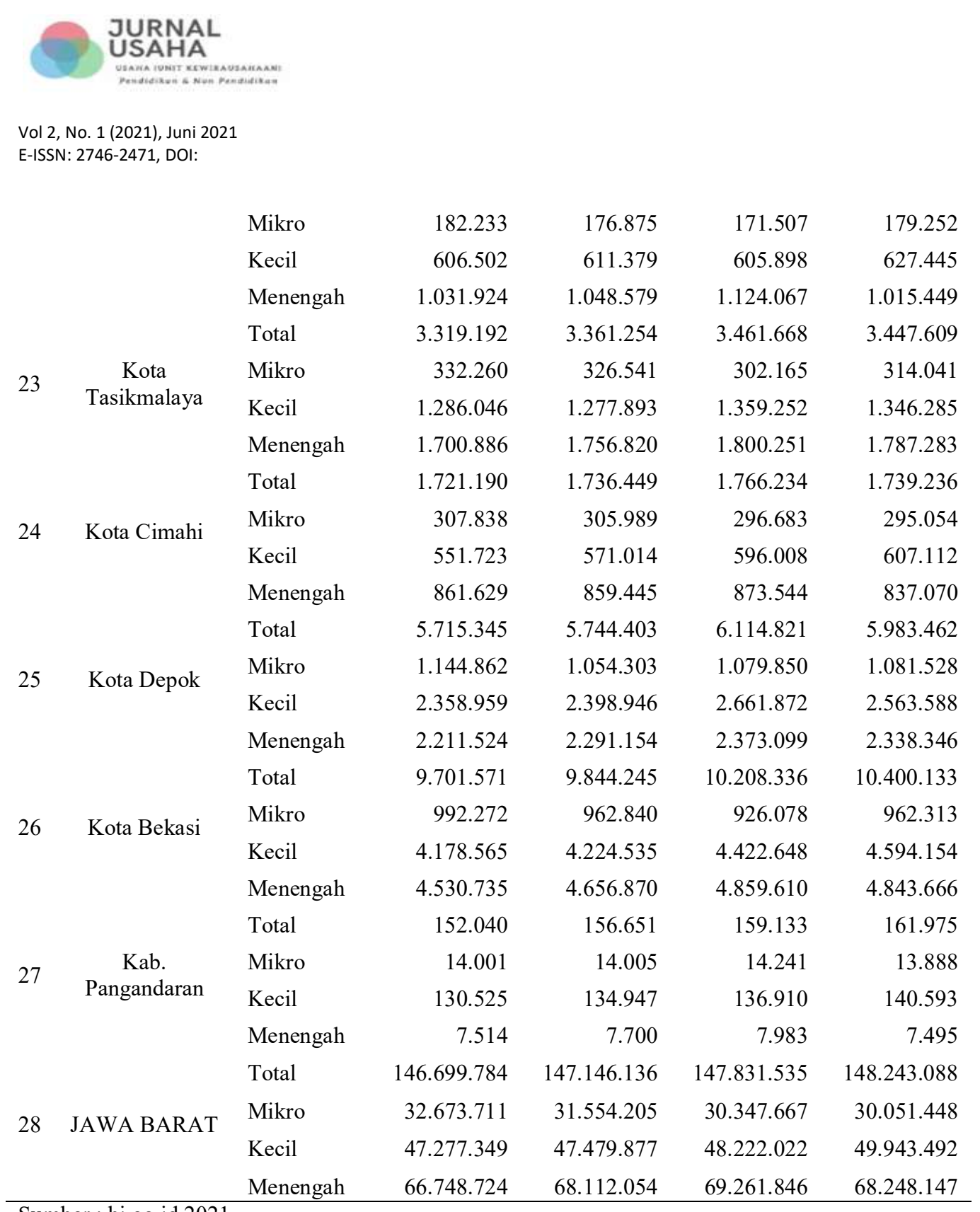

Sumber : bi.go.id.2021 
Vol 2, No. 1 (2021), Juni 2021

E-ISSN: 2746-2471, DOI:

Tabel 2. Kredit Usaha Wilayah Kabupaten Dan Kota Di ProvinsiJawa Barat April - Desember 2020

\begin{tabular}{|c|c|c|c|c|c|c|c|c|c|c|c|}
\hline \multirow{2}{*}{\multicolumn{3}{|c|}{ Kota/Kabupaten dan Kriteria Usaha }} & \multicolumn{9}{|c|}{2020} \\
\hline & & & Apr & May & Jun & Jul & Aug & Sep & Oct & Nov & Dec \\
\hline \multirow{4}{*}{1} & \multirow{4}{*}{ Kab. Bekasi } & Total & 16.132 .328 & 15.822 .168 & 15.539 .480 & 15.607 .042 & 15.767 .787 & 15.842 .996 & 15.387 .133 & 15.408 .055 & 15.443 .227 \\
\hline & & Mikro & 2.908 .921 & 2.349 .001 & 2.313 .996 & 2.248 .160 & 2.187 .228 & 2.137 .443 & 2.090 .270 & 2.040 .575 & 1.969 .983 \\
\hline & & Kecil & 4.413 .827 & 4.392 .498 & 4.370 .992 & 4.376 .828 & 4.437 .766 & 4.552 .864 & 4.622 .589 & 4.667 .169 & 4.727 .987 \\
\hline & & Menengah & 8.809 .580 & 9.080 .669 & 8.854 .492 & 8.982 .054 & 9.142 .793 & 9.152 .689 & 8.674 .275 & 8.700 .312 & 8.745 .258 \\
\hline \multirow{4}{*}{2} & \multirow{4}{*}{ Kab. Purwakarta } & Total & 2.424 .398 & 2.362 .490 & 2.369 .868 & 2.362 .862 & 2.359 .266 & 2.404 .924 & 2.345 .855 & 2.464 .698 & 2.382 .132 \\
\hline & & Mikro & 950.583 & 939.296 & 916.057 & 881.339 & 848.413 & 819.965 & 796.708 & 765.168 & 734.286 \\
\hline & & Kecil & 856.940 & 842.241 & 840.442 & 847.741 & 854.761 & 883.687 & 920.260 & 933.869 & 956.453 \\
\hline & & Menengah & 616.875 & 580.953 & 613.368 & 633.781 & 656.092 & 701.272 & 628.886 & 765.661 & 691.393 \\
\hline \multirow{4}{*}{3} & \multirow{4}{*}{ Kab. Karawang } & Total & 7.472 .998 & 7.497 .097 & 7.410 .893 & 7.314 .624 & 7.404 .746 & 7.351 .688 & 7.369 .510 & 7.496 .799 & 7.307 .650 \\
\hline & & Mikro & 2.467 .019 & 2.458 .389 & 2.389 .287 & 2.318 .712 & 2.251 .115 & 2.191 .414 & 2.133 .181 & 2.072 .831 & 1.998 .971 \\
\hline & & Kecil & 2.329 .735 & 2.309 .974 & 2.321 .246 & 2.315 .195 & 2.328 .744 & 2.380 .903 & 2.386 .350 & 2.399 .325 & 2.416 .431 \\
\hline & & Menengah & 2.676 .244 & 2.728 .734 & 2.700 .360 & 2.680 .716 & 2.824 .887 & 2.779 .371 & 2.849 .980 & 3.024 .643 & 2.892 .248 \\
\hline \multirow{4}{*}{4} & \multirow{4}{*}{ Kab. Bogor } & Total & 13.609 .366 & 13.050 .683 & 13.096 .779 & 13.127 .021 & 13.066 .638 & 13.362 .393 & 13.365 .153 & 13.465 .445 & 13.293 .944 \\
\hline & & Mikro & 3.497 .275 & 3.136 .062 & 3.087 .869 & 2.981 .913 & 2.879 .563 & 2.813 .431 & 2.744 .246 & 2.663 .831 & 2.574 .315 \\
\hline & & Kecil & 3.657 .163 & 3.560 .834 & 3.567 .452 & 3.586 .577 & 3.549 .971 & 3.716 .640 & 3.809 .587 & 3.843 .275 & 3.813 .156 \\
\hline & & Menengah & 6.454 .928 & 6.353 .787 & 6.441 .458 & 6.558 .531 & 6.637 .103 & 6.832 .322 & 6.811 .320 & 6.958 .339 & 6.906 .472 \\
\hline \multirow{4}{*}{5} & \multirow{4}{*}{ Kab. Sukabumi } & Total & 4.604 .931 & 4.476 .890 & 4.573 .045 & 4.530 .085 & 4.529 .286 & 4.548 .281 & 4.510 .907 & 4.474 .541 & 4.453 .070 \\
\hline & & Mikro & 2.070 .301 & 2.052 .577 & 2.002 .725 & 1.926 .450 & 1.850 .284 & 1.780 .607 & 1.716 .686 & 1.641 .501 & 1.570 .031 \\
\hline & & Kecil & 1.526 .408 & 1.489 .124 & 1.511 .207 & 1.507 .481 & 1.515 .806 & 1.534 .423 & 1.520 .194 & 1.545 .190 & 1.564 .955 \\
\hline & & Menengah & 1.008 .221 & 935.188 & 1.059 .113 & 1.096 .154 & 1.163 .196 & 1.233 .251 & 1.274 .027 & 1.287 .850 & 1.318 .084 \\
\hline \multirow{4}{*}{6} & \multirow{4}{*}{ Kab. Cianjur } & Total & 4.157 .228 & 3.825 .658 & 3.900 .497 & 3.875 .396 & 3.894 .307 & 3.963 .441 & 3.946 .228 & 3.947 .533 & 3.939 .294 \\
\hline & & Mikro & 1.834 .713 & 1.584 .543 & 1.575 .398 & 1.518 .266 & 1.459 .952 & 1.409 .816 & 1.356 .228 & 1.295 .711 & 1.233 .880 \\
\hline & & Kecil & 1.325 .878 & 1.301 .074 & 1.328 .973 & 1.344 .355 & 1.337 .582 & 1.361 .087 & 1.337 .698 & 1.371 .654 & 1.393 .345 \\
\hline & & Menengah & 996.638 & 940.042 & 996.127 & 1.012 .775 & 1.096 .773 & 1.192 .538 & 1.252 .302 & 1.280 .169 & 1.312 .068 \\
\hline \multirow{4}{*}{7} & \multirow{4}{*}{ Kab. Bandung } & Total & 10.698 .601 & 10.268 .186 & 10.322 .894 & 10.286 .995 & 10.294 .770 & 10.448 .103 & 10.551 .701 & 10.686 .243 & 10.693 .756 \\
\hline & & Mikro & 3.525 .913 & 3.435 .717 & 3.383 .302 & 3.264 .652 & 3.169 .549 & 3.087 .172 & 3.006 .281 & 2.974 .118 & 2.781 .195 \\
\hline & & Kecil & 3.111 .438 & 3.097 .912 & 3.124 .640 & 3.144 .148 & 3.169 .865 & 3.252 .206 & 3.268 .248 & 3.354 .861 & 3.427 .868 \\
\hline & & Menengah & 4.061 .250 & 3.734 .557 & 3.814 .953 & 3.878 .195 & 3.955 .357 & 4.108 .726 & 4.277 .172 & 4.357 .264 & 4.484 .693 \\
\hline \multirow{4}{*}{8} & \multirow{4}{*}{ Kab. Sumedang } & Total & 3.357 .187 & 3.298 .901 & 3.314 .973 & 3.350 .275 & 3.504 .334 & 3.609 .030 & 3.687 .532 & 3.702 .324 & 3.629 .629 \\
\hline & & Mikro & 1.784 .963 & 1.769 .694 & 1.725 .884 & 1.674 .532 & 1.630 .116 & 1.579 .102 & 1.538 .740 & 1.487 .756 & 1.419 .153 \\
\hline & & Kecil & 1.058 .233 & 1.032 .606 & 1.038 .623 & 1.060 .987 & 1.201 .478 & 1.234 .954 & 1.282 .375 & 1.304 .725 & 1.279 .222 \\
\hline & & Menengah & 513.991 & 496.600 & 550.467 & 614.755 & 672.740 & 794.973 & 866.417 & 909.843 & 931.254 \\
\hline
\end{tabular}


ol 2, No. 1 (2021), Juni 2021

E-ISSN: 2746-2471, DOI:

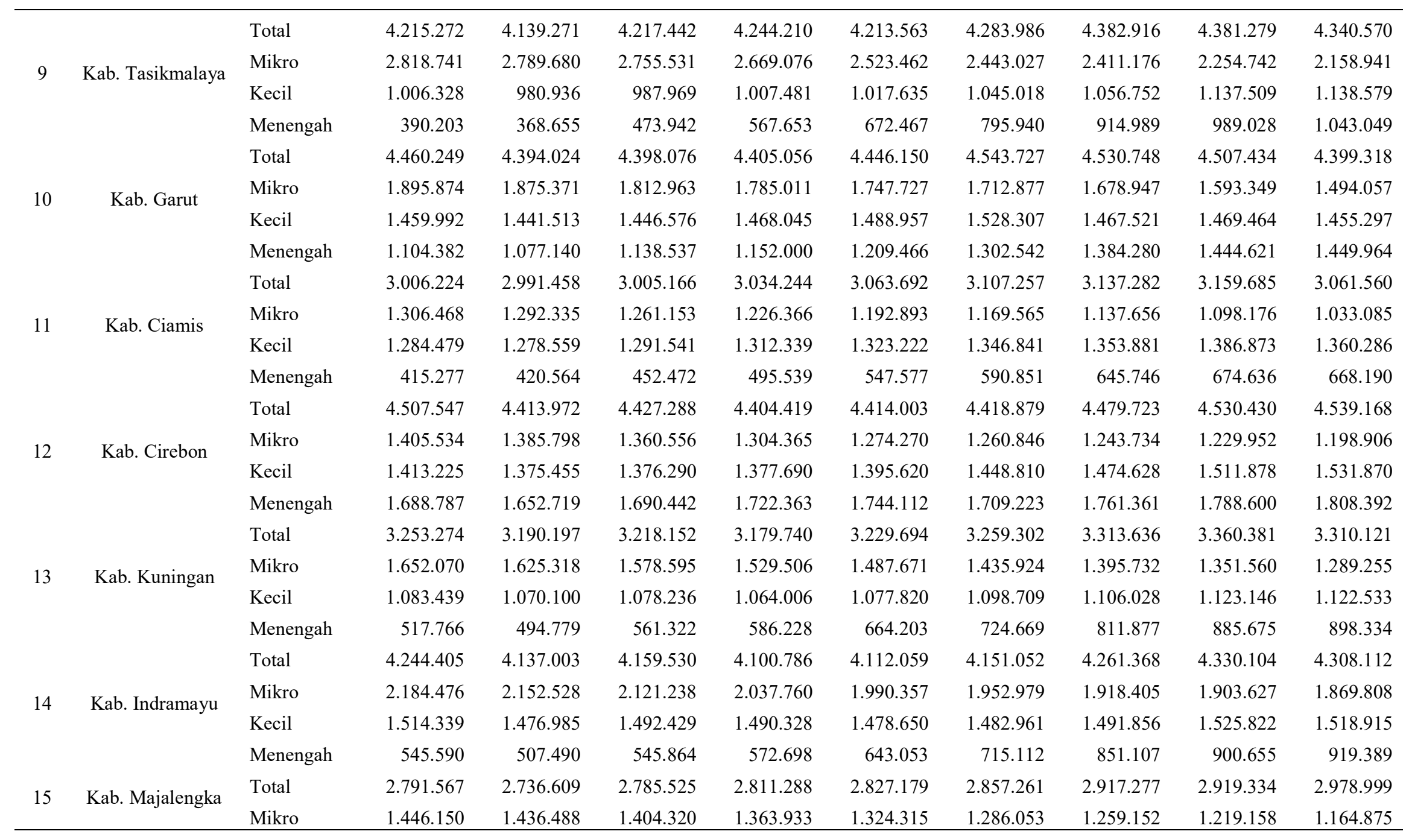

Berta Dian Theodora, KondisiKredit Usaha... $\mid 30$ 
Vol 2, No. 1 (2021), Juni 2021

E-ISSN: 2746-2471, DOI:

\begin{tabular}{|c|c|c|c|c|c|c|c|c|c|c|c|}
\hline & & Kecil & 999.068 & 980.399 & 1.000 .916 & 1.000 .580 & 1.014 .762 & 1.035 .124 & 1.048 .595 & 1.068 .647 & 1.068 .742 \\
\hline & & Menengah & 346.350 & 319.723 & 380.289 & 446.775 & 488.103 & 536.084 & 609.530 & 631.529 & 745.382 \\
\hline \multirow{4}{*}{16} & \multirow{4}{*}{ Kab. Subang } & Total & 4.186 .287 & 4.109 .106 & 4.122 .460 & 4.111 .922 & 4.131 .698 & 4.248 .578 & 4.323 .617 & 4.360 .622 & 4.362 .322 \\
\hline & & Mikro & 2.082 .184 & 2.071 .202 & 2.039 .885 & 1.990 .505 & 1.944 .546 & 1.896 .370 & 1.850 .414 & 1.799 .131 & 1.751 .454 \\
\hline & & Kecil & 1.422 .268 & 1.386 .083 & 1.380 .501 & 1.402 .100 & 1.418 .734 & 1.439 .330 & 1.456 .568 & 1.470 .025 & 1.460 .246 \\
\hline & & Menengah & 681.836 & 651.821 & 702.073 & 719.317 & 768.418 & 912.877 & 1.016 .635 & 1.091 .466 & 1.150 .622 \\
\hline \multirow{2}{*}{17} & \multirow{2}{*}{$\begin{array}{c}\text { Kab. Bandung } \\
\text { Barat }\end{array}$} & Total & 1.757 .875 & 1.736 .618 & 1.684 .920 & 1.691 .311 & 1.576 .182 & 1.594 .417 & 1.593 .838 & 1.580 .024 & 1.593 .634 \\
\hline & & Menengah & 660.199 & 636.706 & 589.868 & 587.706 & 585.109 & 594.559 & 586.445 & 563.708 & 585.859 \\
\hline \multirow{4}{*}{18} & \multirow{4}{*}{ Kota Banjar } & Total & 2.057 .393 & 2.055 .054 & 2.079 .954 & 2.085 .114 & 2.091 .338 & 2.146 .354 & 2.218 .904 & 2.272 .203 & 2.277 .231 \\
\hline & & Mikro & 1.498 .062 & 1.493 .647 & 1.433 .844 & 1.377 .230 & 1.318 .226 & 1.262 .709 & 1.208 .199 & 1.136 .067 & 1.063 .283 \\
\hline & & Kecil & 401.100 & 403.073 & 418.233 & 414.709 & 426.787 & 450.775 & 465.134 & 485.389 & 493.289 \\
\hline & & Menengah & 158.230 & 158.334 & 227.877 & 293.176 & 346.324 & 432.870 & 545.571 & 650.747 & 720.660 \\
\hline \multirow{4}{*}{20} & \multirow{4}{*}{ Kota Bogor } & Total & 4.384 .128 & 4.399 .258 & 4.439 .990 & 4.435 .108 & 4.475 .301 & 4.523 .684 & 4.555 .669 & 4.611 .676 & 4.611 .849 \\
\hline & & Mikro & 555.954 & 586.652 & 625.150 & 686.214 & 729.220 & 772.901 & 813.209 & 919.525 & 958.178 \\
\hline & & Kecil & 1.250 .025 & 1.260 .891 & 1.281 .166 & 1.256 .871 & 1.187 .003 & 1.211 .295 & 1.216 .121 & 1.231 .667 & 1.204 .631 \\
\hline & & Menengah & 2.578 .150 & 2.551 .715 & 2.533 .674 & 2.492 .022 & 2.559 .078 & 2.539 .488 & 2.526 .338 & 2.460 .484 & 2.449 .041 \\
\hline \multirow{4}{*}{21} & \multirow{4}{*}{ Kota Sukabumi } & Total & 1.192 .894 & 1.130 .886 & 1.251 .347 & 1.236 .660 & 1.292 .350 & 1.327 .343 & 1.297 .508 & 1.330 .542 & 1.321 .375 \\
\hline & & Mikro & 271.843 & 257.294 & 258.526 & 249.860 & 245.403 & 258.452 & 250.556 & 244.509 & 236.078 \\
\hline & & Kecil & 411.040 & 392.142 & 419.090 & 426.629 & 447.120 & 454.750 & 445.827 & 457.911 & 456.194 \\
\hline & & Menengah & 510.010 & 481.450 & 573.731 & 560.172 & 599.828 & 614.141 & 601.125 & 628.123 & 629.103 \\
\hline
\end{tabular}


Vol 2, No. 1 (2021), Juni 2021

E-ISSN: 2746-2471, DOI:

\begin{tabular}{|c|c|c|c|c|c|c|c|c|c|c|c|}
\hline \multirow{4}{*}{22} & \multirow{4}{*}{ Kota Cirebon } & Total & 1.955 .727 & 1.893 .366 & 1.886 .481 & 1.876 .065 & 1.857 .318 & 1.887 .600 & 1.865 .891 & 1.867 .960 & 1.871 .587 \\
\hline & & Mikro & 238.046 & 213.920 & 215.747 & 206.876 & 200.820 & 196.196 & 192.099 & 191.475 & 184.167 \\
\hline & & Kecil & 610.396 & 581.180 & 615.002 & 583.041 & 573.236 & 589.320 & 600.030 & 606.376 & 605.001 \\
\hline & & Menengah & 1.107 .284 & 1.098 .267 & 1.055 .733 & 1.086 .148 & 1.083 .262 & 1.102 .083 & 1.073 .762 & 1.070 .110 & 1.082 .420 \\
\hline \multirow{4}{*}{23} & \multirow{4}{*}{ Kota Tasikmalaya } & Total & 3.500 .990 & 3.431 .720 & 3.411 .519 & 3.411 .839 & 3.495 .179 & 3.552 .894 & 3.520 .516 & 3.452 .101 & 3.380 .551 \\
\hline & & Mikro & 452.733 & 450.618 & 369.794 & 364.273 & 413.185 & 410.185 & 355.438 & 349.571 & 340.062 \\
\hline & & Kecil & 1.253 .250 & 1.213 .796 & 1.206 .572 & 1.205 .405 & 1.218 .707 & 1.235 .287 & 1.250 .767 & 1.258 .604 & 1.245 .119 \\
\hline & & Menengah & 1.795 .008 & 1.767 .306 & 1.835 .153 & 1.842 .161 & 1.863 .286 & 1.907 .422 & 1.914 .311 & 1.843 .926 & 1.795 .370 \\
\hline \multirow{4}{*}{24} & \multirow{4}{*}{ Kota Cimahi } & Total & 1.890 .728 & 1.846 .254 & 1.874 .593 & 1.741 .702 & 1.773 .572 & 1.791 .822 & 1.794 .008 & 1.768 .461 & 1.762 .823 \\
\hline & & Mikro & 520.817 & 499.330 & 493.534 & 371.982 & 362.358 & 352.204 & 344.043 & 333.182 & 323.523 \\
\hline & & Kecil & 523.673 & 511.402 & 522.356 & 521.237 & 526.400 & 545.723 & 546.361 & 559.763 & 567.695 \\
\hline & & Menengah & 846.238 & 835.521 & 858.703 & 848.483 & 884.814 & 893.895 & 903.604 & 875.516 & 871.606 \\
\hline \multirow{4}{*}{25} & \multirow{4}{*}{ Kota Depok } & Total & 5.838 .928 & 5.787 .229 & 5.836 .750 & 5.833 .199 & 5.816 .542 & 5.780 .135 & 5.791 .990 & 5.798 .096 & 5.779 .963 \\
\hline & & Mikro & 1.415 .722 & 1.358 .300 & 1.337 .341 & 1.299 .574 & 1.269 .164 & 1.246 .455 & 1.224 .993 & 1.211 .744 & 1.185 .380 \\
\hline & & Kecil & 2.207 .752 & 2.254 .537 & 2.262 .875 & 2.276 .350 & 2.288 .972 & 2.293 .425 & 2.303 .647 & 2.303 .762 & 2.304 .774 \\
\hline & & Menengah & 2.215 .453 & 2.174 .393 & 2.236 .534 & 2.257 .274 & 2.258 .407 & 2.240 .254 & 2.263 .350 & 2.282 .589 & 2.289 .809 \\
\hline \multirow{4}{*}{26} & \multirow{4}{*}{ Kota Bekasi } & Total & 9.808 .436 & 9.623 .758 & 9.627 .971 & 9.593 .345 & 9.507 .995 & 9.518 .746 & 9.663 .471 & 9.786 .289 & 9.766 .881 \\
\hline & & Mikro & 1.265 .169 & 1.197 .346 & 1.180 .113 & 1.144 .379 & 1.115 .619 & 1.093 .899 & 1.074 .473 & 1.073 .809 & 1.047 .764 \\
\hline & & Kecil & 3.945 .378 & 3.911 .158 & 3.907 .072 & 3.927 .263 & 3.926 .295 & 3.956 .068 & 4.011 .195 & 4.059 .247 & 4.134 .265 \\
\hline & & Menengah & 4.597 .889 & 4.515 .254 & 4.540 .787 & 4.521 .703 & 4.466 .082 & 4.468 .779 & 4.577 .803 & 4.653 .233 & 4.584 .852 \\
\hline \multirow{4}{*}{27} & \multirow{5}{*}{ Kab. Pangandaran } & Total & 150.244 & 147.798 & 143.074 & 145.526 & 147.352 & 152.293 & 147.425 & 148.208 & 149.570 \\
\hline & & Mikro & 15.822 & 14.474 & 13.739 & 13.674 & 13.751 & 14.015 & 14.202 & 14.220 & 14.613 \\
\hline & & Kecil & 115.393 & 114.949 & 112.832 & 115.424 & 116.906 & 121.494 & 123.429 & 126.091 & 127.422 \\
\hline & & Menengah & 19.030 & 18.374 & 16.503 & 16.427 & 16.695 & 16.784 & 9.794 & 7.898 & 7.534 \\
\hline \multirow{5}{*}{28} & & & 150.958 .42 & 147.378 .25 & 147.494 .34 & 147.009 .25 & 147.406 .76 & 148.839 .12 & 148.394 .37 & 149.120 .77 & 147.584 .03 \\
\hline & \multirow{4}{*}{ JAWA BARAT } & Total & 9 & 1 & 3 & 2 & 7 & 1 & 9 & 4 & 9 \\
\hline & & Mikro & 43.184 .128 & 41.217 .432 & 40.432 .470 & 39.234 .307 & 38.168 .121 & 37.281 .196 & 36.384 .155 & 35.433 .282 & 34.135 .135 \\
\hline & & Kecil & 44.712 .083 & 44.141 .215 & 44.394 .760 & 44.501 .313 & 44.628 .366 & 45.622 .051 & 46.025 .933 & 46.728 .257 & 46.857 .538 \\
\hline & & Menengah & 63.062 .218 & 62.019 .605 & 62.667 .112 & 63.273 .632 & 64.610 .280 & 65.935 .874 & 65.984 .292 & 66.959 .234 & 66.591 .367 \\
\hline
\end{tabular}

Sumber: bi.go.id.2021 


\section{Daftar Pustaka}

Abdullah, dan Suseno. (2004). KebijakanPerbankan, PPSK, Bank Indonesia.

Anggraini, D dan Haryadi. (2020). Analisisperankreditperbankandalampendanaanusahamikro, kecil, dan menengah (UMKM) sertahubungannyadenganpertumbuhanekonomi di Provinsi Jambi. JurnalParadigmaEkonomika Vol.15.No.2, Juli -Desember 2020. Hal 277 - 286

Apriyanti, M. E. (2020). PercayaDiri Dan BerpikirStrategisUntukMenghadapiKetatnyaPersainganBisnis. Jurnal Usaha Vol 1, No. 2, Desember 2020 Hal 26-40. DOI: https://doi.org/10.30998/juuk.v1i2.482

Ardiansyah, T. (2020). Model Platform E-Commerce DalamMendukungKesuksesan UMKM Di Indonesia. Jurnal Usaha Vol 1, No. 1, Juni 2020 Hal 1-12.

DOI: https://doi.org/10.30998/juuk.v1i1.286

Bi.go.id.https://www.bi.go.id/id/statistik/ekonomikeuangan/sekda/StatistikRegionalDetail.aspx?idprov=32 . Diakses 10 Juni 2021. Pukul 08.20

Boediono. (2000). EkonomiMoneterEdisi 3. BPFE UGM : Yogyakarta.

Goeltom, M.S. (2005). KebijakanPerbankandalamMendukungUpayaPengembangan Usaha Mikro, Kecil dan Menengah, Makalahdisampaikandalam seminar nasional, diselenggarakan oleh Pimpinan Pusat HimpunanPengusahaPribumi Indonesia (DPP-HIPPI)

Jabar.bps.go.id https://jabar.bps.go.id/indicator/6/445/1/tingkat-pengangguran-terbuka-tpt-menurutkab-kota.html. Diakses pada 10 Juni 2021. 08.53

Kasmir. (2013). Bank dan Lembaga KeuanganLainnya. Edisi 1. Jakarta : RajawaliPers

Kontan.co.id. 2021, Maret 31. Jaditumpuan, perbankanfokussalurkankredit UMKM. https://keuangan.kontan.co.id/news/jadi-tumpuan-perbankan-fokus-salurkan-kreditumkm?page $=2$

Laena, I. (2010). Membedah UMKM Indonesia: Sebuah Kajian TentangStrategiPemberdayaan\&Pengmebangan Usaha Mikro Kecil Menengah di Indonesia, Jakarta: Lugas Foundation.

Marti'ah, S. (2021).Penduduk, AngkatanKerja, PenyerapanTenaga Kerja Pada Sektor Usaha Mikro, Kecil Menengah (UMKM) Di Jawa Barat. Jurnal Usaha Vol 1, No. 2, Desember 2020 Hal 1-10. DOI: https://doi.org/10.30998/juuk.v1i2.500

OECD. (2005). OECD SME and Entrepreneurship Outlook: 2005, Paris: OECD.

Permana, S.H., (2017). StrategiPeningkatan Usaha Mikro, Kecil Dan Menengah(UMKM) di Indonesia. JurnalAspirasi Vol. 8 No. 1, Juni 2017 Hal 93-103

Putra, Ayudyas P. Dan I Ketut S. (2018). PengaruhKredit Usaha Rakyat, Tingkat Pendidikan Pengusaha, Dan KewirausahaanTerhadapProduktivitas UMKM KabupatenGianyar. EJurnalEkonomi Pembangunan UniversitasUdayana Vol.7, No.8 Agustus 2018. Hal 1796-1825

Republika.co.id. (2020), Oct 30. OJK CatatPenyaluranKredit UMKM Naik jadiRp. 1.015 Triliun. https://www.republika.co.id/berita/qj06hm423/ojk-catat-penyaluran-kredit-umkm-naik-jadirp-1015-triliun

Undang - undangn No.10 Tahun 1998 tentangperubahanatas UU No.7 tahun 1992 tentangPerbankan

Undang-UndangRepublik Indonesia Nomor 20 Tahun 2008 Tentang Usaha Mikro, Kecil, Dan Menengah

Veithzal, R. dan Andria P. Veithzal. (2007). Bank and Financial Institution Management, Jakarta: PT Raja GrafindoPersada 